\title{
perspectivas en crisis: transformaciones en el comportamiento empresarial a partir de la experiencia de la crisis de 1890 - el caso del sector inmobiliario (rosario, argentina) ${ }^{1}$
}

\author{
Norma S. Lanciotti \\ Universidad Nacional de Rosario \\ Facultad de Ciencias Económicas y Estadística \\ nlanciot@sinctis.com.ar
}

\section{RESUMEN}

La inesperada emergencia de la crisis financiera argentina de 1890 en un contexto de crecimiento económico provocó sustanciales transformaciones en el comportamiento de los empresarios e inversores inmobiliarios. Las dificultades financieras de los agentes comprometidos con el negocio especulativo durante la década del ochenta y la quiebra de quienes hasta entonces habían sido exitosos hombres de negocios, pusieron en evidencia la debilidad de las estrategias empresariales y la inestibilidad de los mecanismos de mercado que habían posibilitado la expansión de la inversión inmobiliaria precedente. El artículo examina eí impacto de la crisis del noventa en el sector inmobiliario urbano y sus efectos en las prácticas e instituciones económicas mediante el análisis de las trayectorias de los agentes inmobiliarios que operaban en la ciudad de Rosario.

Palabras clave: Crisis financiera, empresariado inmobiliario, 1890 , mercado inmobiliario urbano, Argentina.

\begin{abstract}
RESUMO
A inesperada emergencia da crise financeira argentina de 1890 em um contexto de crescimento económico provocou substanciáis transformares no comportamento dos empresarios e dos investidores imobiliários. As dificuldades financeiras dos agentes comprometidos com o negócio especulativo durante a década de oitenta e a falencia diqueles que, até então, tinham sido homens de negocios de sucesso, evidenciaram a flaqueza das estrategias empresariais e a instabilidade dos mecanismos de mercado que tinham possibilitado a expansão do investimento imobiliário precedente. $\mathrm{O}$ artigo examina o impacto da crise de noventa no setor imobiliário urbano e seus efeitos nas práticas e nas instituições econômicas, mediante a análise das trajetórias dos agentes imobiliários que operavam na cidade de Rosario.
\end{abstract}

Palavras-chave: crise financeira, empresariado imobiliário, 1890, mercado imobiliário urbano, Argentina.

${ }^{I}$ Este trabajo ha contado con el ap del mismo se presentó en las XIXJornadas de Historia Económica, realizadas en San Martín de los Andes, en octubre de 2004. 
La prosperidad de la economía argentina en los años ochenta alentaba expectativas favorables en inversores locales y foráneos. No obstante, el optimismo de los inversores pronto sería socavado por la crisis financiera de 1890. Artífice de significativas transformaciones tanto en el ámbito de la políticas como de las prácticas económicas, la crisis impuso al gobierno una serie de reformas fiscales y monetarias, a la par que propició el retorno del debate entre proteccionismo y librecambismo en términos similares a los expuestos en ocasión de la crisis de 1873 (Chiaramonte, 1986; Fernández López, 2000; Botana y Gallo, 1997, p. 71; Rocchi, 1998).

En lo que refiere a las políticas económicas, para contrarrestar la caída de la recaudación impositiva, el gobierno fijó el pago en pesos oro o su equivalente en papel de los derechos de importación e introdujo impuestos al consumo y un impuesto a la exportación. En función de limitar la emisión y controlar la oferta monetaria se crearon instituciones como la Caja de Conversión y el Banco de la Nación Argentina, que definieron los límites del esquema de convertibilidad que regiría el funcionamiento del sistema bancario y del régimen monetario entre 1899 y $1914^{2}$.

Del mismo modo, la crisis de 1890 alteró significativamente el universo de las prácticas económicas. En particular, nos referimos a las estrategias comerciales, pautas de inversión y formas de organización de de las empresas que atravesaron dicha coyuntura, cuestión que constituye el centro de este artículo. No es nuestro objetivo aquí examinar las causas de la crisis del noventa, sino analizar sus consecuencias en el nivel de las prácticas económicas, especialmente en aquellas ejercidas por el empresariado inmobiliario de la ciudad de Rosario. Nuestro planteo procura recuperar la función del acontecimiento en la marcha de los procesos. En este sentido, el examen de los efectos de la crisis del noventa sobre los distintos sectores urbanos nos permite descubrir las prácticas de los actores en relación con las contingencias y las coyunturas. Asimismo, la operación de reinterpretar los procesos económicos situando el eje en la crisis tiene la intención de desplegar un análisis de

2 La Caja de Conversión fue creada en octubre de 1890, bajo la gestión del ministro de Hacienda de Pellegrini, Vicente Fidel López, con la función de monopolizar la emisión de moneda y efectuar la conversión del dinero de curso legal. Entre los factores que habían contribuido a la expansión de la oferta monetaria en los años ochenta, cabe mencionar la Ley de Bancos Garantidos (1887) que otorgaba a los Bancos Provinciales la facultad de emitir moneda (Della Paolera y Taylor, 2003, p. 117). El Banco Nacional entró en liquidación durante la crisis y fue refundado como Banco de la Nación en noviembre de 1891. 
las prácticas que integre a los procesos económicos, las representaciones construidas por los actores en el transcurso de su experiencia ${ }^{3}$.

Por estas razones, procuraremos identificar en qué medida la crisis alteró la perspectiva de los empresarios sobre el funcionamiento del mercado inmobiliario y la incidencia de estas percepciones en las decisiones de inversión y financiamiento así como en la organización de los negocios inmobiliarios en el espacio urbano de entresiglos. En principio se identificarán los efectos inmediatos de la crisis en el sector, dando cuenta del desempeño de los actores y la continuidad de sus negocios en cada caso. Nos detendremos luego en las opciones ensayadas durante la crisis, analizando la lectura de la experiencia de la inestabilidad monetaria y financiera, y su incidencia sobre las preferencias de inversión y la selección de la clientela. Finalmente, revisaremos los criterios de confiabilidad que regían las relaciones comerciales en el sector inmobiliario y los cambios en la organización de los negocios.

A modo de hipótesis de trabajo, consideramos que las estrategias desplegadas y los resultados obtenidos por los empresarios inmobiliarios en el nuevo siglo no sólo dependieron de los recursos disponibles, $i$. e., la composición y magnitud del capital económico, la organización de los negocios y la estructura de las redes sociales; sino también de la adopción de una nueva perspectiva sobre los destinos de inversión más convenientes en función de los factores de riesgo e incertidumbre expuestos por la crisis.

Un breve comentario en torno a las fuentes utilizadas en este trabajo. Para estudiarlos efectos de la crisis en el sector, procedimos a reconstruir las trayectorias de distintos agentes inmobiliarios sobre la base de información provista por fuentes de distinto tipo: archivos de empresas, archivos judiciales, archivos notariales, informes y censos municipales y prensa periódica ${ }^{4}$. Para analizar las reacciones de los inversores frente a la crisis, los expedientes judiciales sobre demandas y pedidos de mora-

3 La ciudad de Rosario (provincia de Santa Fe) era entonces la segunda ciudad del país en términos demográficos y económicos. "Esta posición era consecuencia de su posición estratégica como puerto exportador de la producción agrícola de la región pampeana santafesina.

Sobre los factores desencadenantes de la crisis del 90 en Argentina, véase Ford (1966); Williams (1969); Cortés Conde (1989); Della Paolera y Taylor (2003). Un análisis sobre las representaciones de lo económico durante este período, en Salvatore (2001). Sobre los efectos de la crisis en el ámbito de las prácticas políticas, Bragoni, 2003, p. 67.

4 La reconstrucción de las trayectorias empresariales se desarrolló en el marco de la investigación que culminó en mi tesis de doctorado: Lanciotti, 2004, Introducción y Anexo Metodológico. 
toria constituyeron una fuente de primer orden. Finalmente, el examen de las representaciones de la crisis y su relación con las ideas económicas del período requirió la evaluación de un conjunto variado y extenso de fuentes primarias y secundarias de distinto tipo. Entre las primeras, los diarios y publicaciones locales y nacionales; entre las segundas cabe mencionar el análisis de la crisis efectuado por economistas contemporáneos a ella ${ }^{5}$.

\subsection{9-1892: Continuidades y rupturas en las representaciones de una economía en crisis}

En los años comprendidos entre los comienzos de la crisis y su liquidación, la opinión registrada en la prensa no oficialista respecto de la situación económica del país y la responsabilidad del gobierno conservador presentó variantes en lo que refiere al alcance y profundidad de la crisis y su relación con la política de gobierno ${ }^{6}$.

La primera señal de alerta fue el aumento del premio del oro. En el transcurso del año 1889, las editoriales del diario local El Municipio ${ }^{7}$. mencionaban con preocupación la subida del oro, que atribuían al excesivo gasto público y al consumo privado de bienes importados. En un diagnóstico inicial que describía una situación pasajera, producto de un desequilibrio circunscripto a las esferas monetaria y financiera, la prédi-

5 Se consultaron las siguientes publicaciones periódicas: La Nación, La Prensa, The Standard and River Plate News, The Review of the River Plate, todas ellas de la ciudad de Buenos Aires, y El Municipio, de Rosario. Entre los estudios económicos publicados durante el período en estudio, se destaca Terry (1893).

${ }^{6}$ Un análisis reciente destaca la diferente idea de progreso que en el seno del partido gobernante (PAN) evidenciaban los discursos roquista y juarista durante los años 80 . Mientras que el portavoz del primero, La Tribuna Nacional, aludía al progreso como el medio que lograría solucionar problemas institucionales, morales y políticos del país; en el segundo, el progreso refería al orden material, siendo fin en sí mismo (Alonso, 2003, 2004).

7 El Municipio (Rosario, 1887-1911) era dirigido por Deolindo Muñoz, quien desplegó una posición crítica hacia el conservadurismo provincial, aunque sus argumentos no se subordinaron en principio a un discurso partidario, como se puede apreciar en las sucesivas editoriales. Años atrás, Muñoz había sido partidario del iriondismo, una facción política liderada por el gobernador del partido conservador en Santa Fe, aliado del roquismo. Luego de la muerte de Simón de Iriondo (1883), se produjo una escisión en el conservadurismo santafesino, alzándose con el gobierno la facción contraria a la liderada por Muñoz. No hay precisiones sobre las razones que motivaron su paso a la oposición cívica, lo cual sucedió durante el año 90. Desde entonces, su posición fue afín a la línea de Leandro Alem. 
ca periodística se concentraba en señalar los casos de corrupción administrativa expresada en indiscriminadas concesiones fiscales y mal uso de los fondos públicos sacrifican los intereses generales en aras de los particulares ${ }^{8}$, En una tónica similar aunque más enfática sobre la responsabilidad del gobierno encabezado por Miguel Juárez Celman (1886-1890), el diario mitrista La Nación afirmaba:

No hay empero síntomas definidos que nos anuncien una perturbación. El crédito del país está en auge en el exterior y nuevos e importantes capitales se incorporan a la orbe colosal de nuestro progreso, al paso que la inmigración aumentó y la producción crece considerablemente.

Es cierto que el oro se mantiene altísimo que tiende siempre a subir, pero este estado de cosas no es efecto de la situación general del país, que es en extremo buena, sino de la falta de administración escrupulosa y severa de la cosa pública, por una parte, y del déficit de nuestro comercio internacional, por otra parte, que a causa de la mala cosecha de cereales asciende alrededor de treinta millones de pesos $[\ldots]$.

Nuestra situación general fuera otra, si no hubiese exageración en la importación de mercaderias, bastante despilfarro en las rentas públicas y recargo excesivo del crédito exterior?

La confianza en la natural superación del coyuntural problema monetario y financiero en función de las riquezas del país integraba la percepción construida en torno a la situación por parte del gobierno y de la oposición. A finales del año '89, El Municipio reproducía en tono confiado, el discurso del periódico juarista Sud América, promocionando el aumento de la renta nacional y de las exportaciones, y la instalación de líneas férreas, como respuesta a los que se regocijan ante la pretendida ruina del país y anuncian como un triunfo la pérdida de las cosechas ${ }^{10}$. En su

tiembre de 1889 .

8 "Enajenación de tierras nacionales", El Municipio, año III, n. 690, Rosario, 2

9 "Situación general de los negocios", La Nación, Año XX, n. 5653, Buenos Aires, jueves 25 de abril de 1889 , p. 1.

10 "La situación económica de la nación", El Municipio, Año II, n. 770, Rosario, 29 de diciembre de 1889. Sud América apareció por primera vez en mayo de 1884. En el emprendimiento, participó Carlos Pellegrini, quien fuera vicepresidente de Juárez Celman. El diario adhirió a la candidatura de este último, y a partir de su triunfo se convirtió en el órgano de prensa del presidente (Alonso, 2004). 
argumentación, la victoria de la "economía real" sobre la especulación financiera y las restricciones del crédito se debía a la posición comercial de la ciudad y el crecimiento de la producción agropecuaria en la provincia de Santa Fe, lo cual sumado al "espíritu emprendedor de sus habitantes" bastaría para sostener el primer puesto que Argentina exhibía entre sus pares latinoamericanas. Una editorial del $1^{\circ}$ de enero de 1890 mencionaba las amplias posibilidades de superar el momentáneo "tropiezo".

El comercio, la industria, la exportación, son los grandes factores de la prosperidad nacional. Las finanzas y el crédito, no obstante las perturbaciones del momento que podían ser obviadas á fuerza de tino gubernamental - perturbaciones que pueden ser aceptadas como una enseñanza que ha de ser aprovechada por los gobiernosno han experimentado un desequilibrio tal que pueda alarmarnos, pero sí predisponernos al mayorjuicio, á gobierno como á gobernados, uno y otros en la esfera que corresponde a cada cual en la labor común que no es otra que cimentar la estabilidad del país prosiguiendo un sistema económico sensato que eluda las dificultades que son una consecuencia de la imprevisión o de la tendencia a preocuparse exclusivamente del presente sin mirar hacia el porvenir.

Pero estos trastornos del momento, como tales transitorios - ocasionados sin duda alguna por el afan de las riquezas improvisadas que ha dejenerado en el delirio de la especulación más allá de lo útil y conveniente para el país - no nos ha hecho perder el puesto de primera final en relación con los demás países latinoamericanos.

La provincia de Santa Fe, sola, en comercio y crédito, parangonada con algunas naciones de Sud América, ocupa el puesto de referencia.

La nación, pues, prosigue en marcha hacia un porvenir halagador, sin que dificultades transitorias más o menos subsanables a fuerza de patriotismo, abatan el espíritu de sus habitantes, que siempre interesados en que la prosperidad nacional no se resienta, ha de seguir viviendo para el trabajo que es la expresión que sintetiza la aspiración común ${ }^{11}$.

La percepción de la crisis como fenómeno transitorio y circunscripto fue también alentada por las entidades financieras que negociaban títulos públicos, cédulas hipotecarias y acciones de las compañías británicas en el mercado de Londres. Como reacción a las primeras noticias alar-

11 "1889-1890", El Municipio, Rosario, año III, n. 772, miércoles 1 de enero de 1890. 
mantés publicadas en la prensa londinense, este sector procuraba tranquilizar a su clientela reafirmando la confianza en la política gubernamental'". No obstante, los síntomas de una crisis en ciernes eran visibles para los tenedores de cédulas tal como lo refiere el siguiente comentario, publicado en The Standard:

As long as the stock-brokers and the newspapers were agreed in praising the Argentine Republic all went well, At present, they take the opposite side,. the newpapers howling, the stock-brokers aplauding. The latter are afraid to advise their clients to sell out, least all Argentine securities to go down with a run,

What tends the more to alarm Londoners is thefact that Mr. Varela's drastic measures have not mended matters, but thatgold is running upfaster than befare. The people who have bought Cedulas are of course the most frightened at all since they see both their capital and interest dwindling down day by day. Afellow passenger with mefrom Montevideo told me that he bought Cedulas at gold prices in 1883, and in five years lost 36 per cent of his capital $[\ldots]^{13}$.

Por cierto, la expectativa en un retorno natural al equilibrio era debatida en las páginas del diario The Standard, órgano de la comunidad mercantil británica en Argentina, donde al menos desde agosto del año '89, se expresaban reservas respecto a la magnitud del problema y la capacidad del gobierno argentino para resolverlo ${ }^{14}$. El promotor principal de la línea critica a la visión optimista era el editor y periodista, Michael G. Mulhall, quien había integrado el grupo de asesores del presidente

12 "We tnust be prepared to face a situation when several provinces are spending the proceeds of foreign loans, and when the so-called free banks will be in full swing. Under such circunstantes rising in the nearfuture, it will need a strong hand to steer the financial ship through the shoals around; but we doubt not that the Finance Minister is well aware of all these dangers and difficulties, and will frame a policy to meet emergencies and tide over situations of the most delicate nature" The Standard, XXX, n. 8086, Buenos Aires, July 19, 1889, p. 1.

13 The Standard, XXX, n. 8104, Buenos Ayres, august 9, 1889.

14 "The continuous rise in the gold premium at Buenos Ayres serves to accentuate the apprehensions for some time prevalent that the Argentine Republic is approaching to monetary and financial crisis." The Standard, XXX, n. 8124, Buenos Ayres, september 3th, 1889. 
Nicolás Avellaneda (1874-1880) durante la crisis de 1873-1876 ${ }^{15}$. Como respuesta a una nota aparecida en The Standard, donde se manifestaba que "el enfermo ya pasó el momento crítico y que puede ser ahora considerado convaleciente", en su carta del 5 de enero de 1890, Mulhall afirmaba que esta nueva crisis, lejos de haber pasado, todavía no había comenzado. Recomendaba abandonar las teorías que explicaban la crisis como resultado de causas extrañas al accionar del gobierno, puesto que su origen se remontaba a la suspensión de la convertibilidad en 1885 dispuesta por el presidente Julio A. Roca (1880-1886). En su opinión, la única medida conducente a estabilizar la situación era un retorno a la convertibilidad que fijara la emisión en las reservas metálicas.

La riqueza y la moneda son dos cosas tan distintas como lo son los caballos y los cañones, sin embargo de que algunas veces suelen hallarse ligados - cuando se dictan leyes sobre una $u$ otra, necesario es que el legislador concentre toda su atención sobre la ultima; pero también es verdad, cuanto menos se legisla sobre la materia, tanto mejor, salvo en los casos en que se trata de castigar a monederos falsos o a los que emitan valores ilegales. - Tratándose del medio circulante, es cuestión completamente accesoria de que un país sea rico o pobre $[\ldots]$.

Se encuentran, pues uds, en vísperas de una crisis tremenda, si no establecen de una vez su emisión bajo una base segura, el sistema de las microscópicas quemas mensuales tampoco daría mejores efectos que los que han tenido en Chile. La confianza del público no ha desaparecido aún del todo; sin embargo, de que los acontecimientos de los últimos 5 años la han sacudido; - el haberse dispuesto de las reservas de oro, la emisión ilimitada de cédulas, las garantías a ferrocarriles en competencia; todas estas son cosas que han producido los efectos más desastrosos ${ }^{16}$.

Michael G. Mulhall, nacido en Dublin, fundó en Buenos Aires el diario The Standardjunio a su hermano Edward Thomas en el año 1861. Publicó numerosos estudios económicos y estadísticos, entre ellos el Handbook of the River Plate Republics. En 1878, regresó a Europa, dedicándose a la estadística comparada hasta su muerte en 1900 (Fernández Lopez, 2000, p. 115).

"La crisis Argentina. Porvenir económico. Carta del Mr. Mulhall. Londres, enero 5 de 1890", publicada en El Municipio, año II, n. 807, Rosario, 13 de febrero de 1890 . 
Pocos días después, la prensa no oficialista comenzaba a adherir a esta explicación. A finales de enero del 90, una imagen apocalíptica sobre el futuro económico del país apareció por vez primera en las páginas de $E l$ Municipio. Por entonces el diario aún apelaba a una solución proveniente del gobierno, en contraste con La Nación que exigía su prescindencia total ${ }^{17}$. No obstante, en pocos días, creció el rechazo a la política emisionista de Juárez Celman, causante de la depreciación de la moneda y la pobreza de la clase trabajadora a la par que se sucedían las denuncias sobre la corrupción política y administrativa de los gobiernos nacional y provinciales.

En esta coyuntura, las noticias sobre el fracaso de las tentativas del acuerdo del gobierno con los bancos ingleses y franceses para obtener un nuevo empréstito, finalmente socavaron la visión optimista de la crisis. En marzo del 90, la prensa local se hizo eco de los rumores que habían alentado la primera corrida contra el sistema financiero, y dejó de exigir una solución al gobierno para clamar por la renuncia de Juárez Celman ${ }^{18}$.

La renuncia del presidente en agosto de 1890 y la asunción del vicepresidente Carlos Pellegrini (1890-1892) en principio fueron celebradas por la opinión pública, al igual que las primeras medidas anunciadas por el ministro Vicente F. López; pero a finales de ese año, la opinión sobre el gobierno se había tornado desfavorable ${ }^{19}$. Se cuestionaron los efectos de la política fiscal sobre la producción y el comercio, y se responsabilizó a Pellegrini de la humillación argentina frente a los acree-

17 "No es necesario ser profeta para conocer el desastroso fin á que marchamos, si no viene pronto una reacción saludable y salvadora", "El único y la crisis", El Municipio, año III, n. 792, Rosario, 26 de enero de 1890.

18 "Hace mas de tres meses que el comercio de Rosario empezó á murmurar en contra del Banco de la Provincia de Santa Fe, cuya situación no aparecía ni muy clara ni muy próspera [...]. Ante un tal fenómeno por demás extraño, el comercio y todos los depositantes en general, principiaron á retirar sus haberes, debiéndose notar que una tal operación no fue llevada acabo con la rapidez abrumadora propia de la desconfianza y del pánico, sino con una calma digna de alabanza y obedeciendo á una legitima defensa. El Banco Provincial. Su influencia en la crisis. La defensa del comercio", El Municipio, año III, n. 830, Rosario, 14 de marzo de 1890. Desde el mes de abril de $\mathbf{1 8 9 0 , ~ L a ~ N a c i o ́ n ~ c o m e n z o ́ ~ a ~ r e f e r i r s e ~ a ~ u n a ~ d o b l e ~ c r i s i s : ~ e c o n o ́ m i c a ~}$ y política.

19 "Los proyectos financieros. Una institución buena", en El Municipio, año IV n. 954, 20 agosto de 1890 . Un análisis de las medidas del gobierno de Pellegrini en Della Paolera y Taylor, 2003, p. 114. 
dores extranjeros. El rechazo, antes centrado en el "unicato" de Juárez Celman, se hizo extensible al partido gobernante. Las denuncias se dirigieron a Roca, entonces Ministro del Interior y Pellegrini, "pupilo del dictador" y "cómplice de los derrochadores".

En abril de 1891, la suspensión de los pagos de los depósitos y cuentas corrientes y la liquidación de los bancos generaron opiniones ambiguas: las medidas fueron calificadas de inmorales y antipatrióticas, no obstante constituían un paso adelante en la salvación del país. A partir de entonces, se configura el discurso crítico del capital extranjero que pretendía controlar la economía argentina con la anuencia del gobierno, cuya repercusión denunciaba la prensa comercial británica en Argentina ${ }^{20}$.

Respecto a las atribuciones del Estado, el discurso de El Municipio, parecía expresar las tensiones representadas por la adhesión a un liberalismo ortodoxo y la convicción de que sólo el Estado nacional podía ordenar el caos administrativo y financiero. El reclamo sistemático por la introducción de políticas para frenar la depreciación del peso, la opinión favorable respecto a la creación de la Caja de Conversión y a la reapertura del Banco Nacional, los argumentos esgrimidos contra las reformas fiscales de López y el enfático apoyo a la decisión gubernamental de intervenir el Banco de la Provincia de Santa Fe conformaron un abigarrado conjunto de ideas sobre la economía que presentaban al Estado como último garante de la defensa de los intereses de la producción y el comercio, frente a las fluctuaciones económicas derivadas de las acciones perjudiciales ejercidas por funcionarios y agentes económicos en la prosecución de intereses contrarios al bien común ${ }^{21}$.

La indefinición sobre los temas económicos atribuida a la prensa favorable al radicalismo opositor quizás merezca una interpretación similar, a partir de lo cual podríamos identificar una constelación de representaciones producidas y reproducidas por la esfera pública, originadas en la adaptación del pensamiento del liberalismo clásico a las condaciones y fluctuaciones de la economía argentina. Los distintos ele-

20 agosto de 1890. 
mentos convergentes en esta constelación, serían enfatizados por los dirigentes opositores según las circunstancias políticas coyunturales y los alcances generados por el debate parlamentario en torno a las medidas de gobierno ${ }^{22}$.

Durante los años 1889-1891, emergió un incipiente debate público respecto de los beneficios del librejuego de las fuerzas en el mercado así como de las facultades del estado en la regulación de la economía. En este escenario, se identifica una transición en el orden de las representaciones de lo económico a partir de la revisión de los postulados liberales a la luz de la crisis, coincidente por cierto con el clima internacional favorable al proteccionismo que la crisis de 1873 había despertado tanto en el continente europeo como en EEUU. Esta tendencia era particularmente visible en el discurso oficial según puede apreciarse en la crítica de Roca al curso forzoso implementado durante su propia gestión o en los argumentos de Juárez Celman al decretar el cierre de la Bolsa de Comercio para detener la suba del oro, ocasión en la que expuso que la debilidad de la acción privada se había convertido en nociva para la industria y el comercio ${ }^{23}$.

Una formulación precisa respecto a las funciones del Estado en circunstancias de crisis fue la esbozada por José Terry en 1893, cuando afirmaba que el Estado debía proveer a las necesidades que no pudieran ser satisfechas por la iniciativa individual. Habiendo atravesado la fase de liquidación de la crisis, Terry consideraba que la economía comenzaría a recuperarse; por consiguiente era el momento adecuado para reflexionar sobre la acción estatal en el progreso económico de los pueblos. Su análisis tenía presente el proceso europeo y, especialmente, la reacción liberal frente al auge de las políticas proteccionistas en los países continentales. En función de los términos de dicho debate, recomendaba asumir una posición alejada de los extremos, muy cercana al pensamiento de los economistas clásicos, aunque divergente de las ideas liberales divulgadas por la prensa mitrista. Según Terry, debía promo-

22 Sobre la divergencia entre el discurso de la dirigencia y la prensa radical: Rocchi, 1998, p. 118. Sobre el debate parlamentario en los noventa: Botana y Gallo, 1997, p. 71,407 .

Cfr. Botana y Gallo, 1997, p. 43. El señalado pragmatismo de la política económica del gobierno conservador es visible en la evolución del pensamiento de Pellegrini respecto a la creación de un banco estatal (Botana y Gallo, 1997, p, 73). 
verse la acción del Estado, allí donde el interés privado se haya demostrado impotente ${ }^{24}$.

No era esta la opinión de la prensa liberal opositora, representada por el Diario La Nación, cuyos reclamos por la no intervención del gobierno en la economía se habían acrecentado durante 1889 , cuando pregonaba la pronta recuperación de la economía argentina y su natural destino de riqueza y progreso ${ }^{25}$. Un año más tarde, La Nación aceptaba la gravedad de la situación económica sin abandonar el rechazo a toda intervención gubernamental. En su análisis, los factores causantes de la crisis eran resultantes del accionar del gobierno: la liberalidad del crédito público, el curso forzoso y la política emisionista. De modo que la única solución sobrevendría de su liquidación general.

El gobierno, causa principal de estas profundas perturbaciones que afectan el mercado monetario y que refluyen sobre el comercio, es el primero que debe entrar de lleno en la liquidación a fin de concurrir respectivamente a normalización general, ya que prácticamente se ha mostrado que no tiene medios ni capacidad para hacerlo ni la voluntad para intentarlo ${ }^{26}$.

Cfr. Terry, 1893, p. 322. La intervención del Estado en los casos en que las fuerzas competitivas no condujeran a una óptima asignación de recursos estaba presente en la obra de Adam Smith. Además de condenar los monopolios y convenir la regulación del comercio cuando una política librecambista afectara la producción nacional, Smith establecía que en el caso de aquellos bienes de gran utilidad social, cuyo aprovisionamiento no fuera rentable para los privados, era el estado quien debía proveerlos (Smith, 1958, p. Libro V, parte III). Por otra parte, tanto Vicente F. López como Terry y Pellegrini integraron a su lectura de los economistas clásicos, i. e., Smith, Ricardo y Mill, las formulaciones de la Escuela Histórica Alemana respecto a la conveniencia del proteccionismo en los países jóvenes; lo cual abonaba una noción del Estado, distinta a la divulgada por el liberalismo ortodoxo. Sobre el pensamiento económico de López y su generación: Chiaramonte, 1986, p, 121. Sobre el retorno de las ideas mercantilistas en el continente europeo durante el último cuarto del siglo XIX: Pollard, 1992, cap. 7.

En abril de 1889, La Nación reclamaba "que el gobierno no se inmiscuya en la bolsa, que reduzca el presupuesto de gastos en doce millones por lo menos, que renuncie a los empréstitos exteriores y a los ensayos de planes financieros que solo producen conmoción, inseguridad y alarma en el mercado." La Nación, Año XX, n. 5653, Buenos Aires, jueves 25 de abril de 1889. Al mes siguiente, afirmaba "No es posible desconocer la creciente prosperidad, el aumento de la riqueza, el desarrollo vital del país [...]". La Nación, año XX, n. 5677, jueves 23 de mayo de 1889.

La Nación, año XXI, n. 5917, Buenos Aires, martes 4 de marzo de 1890, Editorial, p. 1. 
Por el contrario, el pensamiento económico de la elite conservadora continuó asignando un amplio espacio a la acción del Estado en los noventa, aunque la euforia del progreso cedió paso a una retórica mesurada que se ajustaría a la prosecución del equilibrio fiscal y presupuestario articulado con el diseño de una política monetaria deflacionista (Botana y Gallo, 1997, p. 71). En esta dirección, podría registrarse una convergencia entre la posición del gobierno y la opinión pública respecto de tres cuestiones relacionadas: la necesidad de una moneda estable, la austeridad presupuestaria y la conformación de instituciones estatales que fueran independientes de los vaivenes políticos ${ }^{27}$.

Al respecto, la distinción entre gobierno y estado formulada por Terry, procuraba legitimar una ruptura con la noción de Estado vinculada al orden juarista, condenando el emisionismo, el curso forzoso, el incremento de gastos superfluos y el excesivo crecimiento del empleo estatal, como erróneas políticas de gobierno conducentes a la crisis; claramente contrapuestas a la acción beneficiosa que ejercería la creación de un "verdadero Banco de Estado" (Terry, 1893, p. 327).

\section{De la euforia al crack: efectos de la crisis en el sector inmobiliario}

Entre 1886 y 1889, la expansión del mercado de tierras resultante de la instalación de las redes ferroviarias en la región pampeana santafesina y el incremento de la oferta de crédito disponible a través del sistema de cédulas hipotecarias determinaron la elevada rentabilidad de la compraventa de terrenos urbanos, atrayendo a inversores, operadores ocasionales y propietarios de tierras (Lanciotti, 2003, p. 345). Al mismo tiempo, las bajas tasas de interés y el acelerado incremento de la oferta monetaria por el ingreso masivo de capitales extranjeros en Argentina (Cortés Conde, 1989, p. 210), alentaban la reinversión en terrenos para los propietarios que accedieran al crédito hipotecario, quienes de este modo se aseguraban nuevos préstamos, reforzando la acción inicial sobre el sistema.

La popularidad alcanzada por Pellegrini hacia el final de su presidencia como resultado de su gestión durante la crisis era reconocida por sus opositores, como puede ilustrarse en el comentario de Leopoldo Lugones, quien ironizando sobre los límites políticos del "sportman", se preguntaba porque en 1892, no había asumido "una dictadura que el pueblo hubiera aguantado y hasta aplaudido, de cansado que estaba." Cfr. "Los políticos de este país", La Montaña, Periódico Socialista Revolucionario, n. 1, 1 de abril de 1897 (Ingenieros y Lugones, 1996, p. 25). 
La difusión del sistema de cédulas y las ganancias extraordinarias obtenidas en la compraventa incrementaron la demanda de tierras y elevaron los precios, configurando una dinámica que retroalimentaba el circuito hasta culminar en la crisis del noventa. Por otra parte, el aumentó de la emisión y la disminución de las reservas monetarias que se produjeron durante la presidencia de Juárez Celman generaron expectativas de depreciación monetaria futura; de modo que mientras hubiera crédito, resultaba conveniente endeudarse en moneda nacional (Cortés Conde, 1989, p. 189).

Según el destino dado a los beneficios de la especulación inmobiliaria, la crisis influyó en distinto grado entre los inversores y empresarios. del sector. Afectó en principio, a los poseedores de cédulas hipotecarias cuyo valor se depreció rápidamente por la devaluación monetaria, la deflación de los precios de la tierra y la recesión del mercado inmobiliario. Se pegudicaron del mismo modo las empresas y particulares endeudados en pesos oro o en moneda nacional convertible a peso oro ${ }^{28}$; los operadores que habían adquirido tierras después de 1888 y no pudieron venderlas antes de la caída de los precios ${ }^{29}$. La retracción del flujo de capitales extranjeros y el aumento de los precios relativos de los insumos importados afectó al sector contratista de obras públicas: los empresarios a cargo de las obras del puerto, el adoquinado y el transporte urbano suspendieron los trabajos ${ }^{30}$. Finalmente, los agentes dedicados . exclusivamente al negocio inmobiliario y las empresas financieras cuya clientela estuviera mayormente integrada por los sectores recién mencionados, fueron también afectados por la crisis $^{31}$.

En los años 80, la mayoría de los empresarios del sector desarrollaba además otras actividades económicas. Aproximadamente tres cuartas partes de los inversores se dedicaba al comercio, la producción agropecuaria y la industria (Lanciotti, 2003, p. 351), de modo que la evolución

Funes y Guillermo Kemmis.

${ }^{28}$ V.g. Juan Canals, Enri

${ }^{29}$ V.g. Canals, Emilio Sc

${ }^{30}$ En Rosario, Juan Can

Machain y Cía.

Las propiedades de Emilio Ortiz y Cía., José Puccio, Enrique Middleton, Ricardo Parera y Juan Canals, quedaron en manos de las entidades bancarias acreedoras, a saber, Banco Hipotecario Nacional, Banco Nacional en liquidación, Banco Provincial de Santa Fe, Banco de Londres y Brasil, Banco de Londres y Río de la Plata y Banco Inglés del Río de la Plata. 
de la actividad principal y la proporción del capital involucrado en inversiones inmobiliarias determinó distintas condiciones de negociación y resultados durante el quinquenio posterior a la crisis.

Los exportadores se vieron favorecidos por la depreciación de la moneda nacional que alcanzó su punto más bajo en octubre de 1891, aunque este efecto fue moderado por la caída de los precios internacionales de la lana y el cereal. La baja de los precios externos y las restricciones impuestas por el gobierno brasileño a las importaciones argentinas influyeron negativamente sobre el sector ganadero, cuyo PBI se estancó hasta 1895 (Cortés Conde, 1997, p. 230).

Por el contrario, la caída de los precios del cereal no interrumpió el ascenso de la producción agrícola pampeana: el Producto Bruto Interno del sector agrícola prácticamente se triplicó entre 1889 y 1894 . Durante el quinquenio posterior a la irrupción de la crisis, el volumen del trigo exportado se triplicó y su valor en pesos oro se duplicó (Gerchunoffy Llach, 2003, p. 44). La disminución de los costos internos favoreció entonces a la agricultura; no obstante su expansión sostenida se explica por el incremento de los factores de producción debido a la puesta en funcionamiento de la red ferroviaria pampeana y la incorporación de mano de obra inmigrante (Cortes Conde, 1979, p. 90) ${ }^{32}$.

El comercio importador fue muy afectado por la crisis. Al incremento relativo del precio de los bienes importados por el aumento del premio del oro (de 180 a 358) entre 1889 y 1894, se sumó en 1891, la elevación de los derechos aduaneros dispuesta por el gobierno de Carlos Pellegrini para incrementar la recaudación fiscal resentida por la caída de las importaciones ${ }^{33}$. La disminución de las importaciones y los altos aranceles devinieron condiciones favorables para el desarrollo de la industria de bienes de consumo para el mercado interno que no utilizara materias primas e insumos extranjeros. La inversión en la industria resultó entonces particularmente atractiva para los comerciantes importadores en la medida en que les permitía compensar la caída de su activi-

Las exportaciones totales aumentaron de 195 millones de pesos moneda nacional en el quinquenio 1885-1889 a 234 millones en 1890-1894 y a 298 millones en 1895-1899 (Gerchunoffy Llach, 2003, p. 44). Si el valor de las exportaciones aumentó a pesar de la caída de los términos del intercambio, parece claro que la producción agrícola aumentó en este período, en el que la depreciación del peso dotaba al trigo argentino de competitividad mayor en el mercado internacional. lones en 1890-1894 (Gerchunoffy Llach, 2003, p. 44). 
dad principal, integrando en sus redes de comercialización, los productos elaborados en el país ${ }^{34}$.

La diversificación hacia actividades agrícolas y manufactureras se revelaba pues, un mecanismo apropiado para reducir el riesgo y compensar la caída de los beneficios del comercio importador e inmobiliario en la coyuntura de la crisis. En lo que refiere al sector inmobiliario de la ciudad de Rosario, la estrategia de diversificación económica permitió asegurar el patrimonio y la continuidad de ingresos de un grupo de comerciantes, entre ellos José Arijón, Ciro Echesortu, Luis Pinasco y José Castagnino. Aún aquellos comerciantes y empresarios agropecuarios que se habían endeudado a causa de sus grandes inversiones en tierras urbanas como Emilio Schiffner, Allanson Hall, Gregorio Machain, Emilio Ortiz o Domingo Barraco, pudieron renegociar sus obligaciones con las entidades financieras y recuperarse después de $1895 \backslash$

\section{Los empresarios de la crisis}

\subsection{Domingo Barraco}

La magnitud de las inversiones inmobiliarias y deudas hipotecarias de los comerciantes que especularon con tierras urbanas, pero también las posibilidades de eludir la quiebra por parte de inversores ocasionales bien informados, cuya actividad principal no fuera afectada radicalmente por la crisis, pueden evaluarse a través del caso del comerciante Domingo Barraco.

La tasa de crecimiento del sector industrial para el período $1890-1899$ fue del $11,5 \%$ anual (Cortés Conde, 1997, p. 207). La reinversión de los beneficios del comercio en la actividad industrial inicialmente señalada por Diaz Alejandro (Díaz Alejandro, 2002, p. 214), fue luego confirmada por estudios empíricos (Rocchi, 1994). Sobre las estrategias de los importadores españoles en esta coyuntura, véase Fernández (2004), esp. cap. 3. Sobre el industrial importador, como caso particular del empresariado argentino diversificado, ver Rocchi (1996). Entre los comerciantes importadores que invirtieron en la industria urbana local, pueden citarse los casos de Wildermuth Hnos y Pinasco \& Castagnino y los importadores de yerba mate que instalaron las primeras fabricas de yerba de la ciudad, como Estévez \& Cía y R. Couzier y Cía. No obstante, otros comerciantes continuaron con el negocio de importación, sin diversificar sus actividades luego de la crisis,

35 Pinasco \& Castagnino, Arijón y Echesortu mantuvieron una situación financiera estable, ejerciendo como prestamistas en el primer lustro de los 90. Por otra parte, los empresarios agropecuarios y las compañías de tierras encontraron en el arrendamiento una alternativa provechosa que les proporcionaba buenas ganancias mientras los precios de los lotes se mantuviesen deprimidos (Gallo, 1984, p. 98). 
En el año 1890, frente a una demanda del Banco de Londres por cobro de pesos, el comerciante Domingo Barraco solicitó una moratoria de pago. La demanda se había originado por una deuda que Barraco tenía con su proveedor Barroza y Cía de Montevideo por la suma de \$mn 19.483 en concepto de mercaderías remitidas. Esta deuda fue luego transferida al Banco de Londres y Río de la Plata según circunstancias no mencionadas en el expediente. El pedido de moratoria de Barraco se fundamentaba en los efectos imprevisibles de la crisis, apelando al art. 1584 del Código de Comercio vigente. Los argumentos de la solicitud se centraban en la solvencia comercial y en la capacidad del comerciante para cumplir con las obligaciones según la verificación de los bienes que integraban su patrimonio, siempre que se le otorgara una moratoria de pago ${ }^{36}$.

Como se observa en el Cuadro 1, el pasivo total de Barraco representaba poco más del sesenta por ciento de su activo, que estaba mayormente compuesto por bienes de escasa liquidez, en los que se destaca una importante suma de acreencias por cobrar ( $44 \%$ del activo). Entre las deudas personales que integraban el pasivo había varias hipotecas y pagarés a nombre de las compañías inglesas que operaban en la región, del Banco Provincial de Santa Fe, y de prestamistas locales como Luis Lagomarcino, Ventura Brignardello y José Arijón.

En el detalle de las deudas comerciales se manifiesta la amplia disponibilidad de crédito que el almacén de Barraco tenía entre los importadores locales como Rouillón, Marini y Cía, Pinasco y Castagnino, Schlieppery Cía, Portalis, Freres, Carbonier y Cía. Ledesma Hnos, y las empresas manufactureras como Destilería La Rosario, Fábrica Santafesina de Tabacos y Bagley, además de los créditos habilitados por el Banco Nacional, el Banco de Italia y Río de la Plata y el Banco de España y del Rosario de Santa $\mathrm{Fe}^{37}$.

La evaluación de la solicitud se centró en su activo comercial y aún cuando su patrimonio no llegaba a los $\$ 35.000$ y las deudas por cobrar representaban casi el $80 \%$ del activo comercial, la justicia accedió a la moratoria. Sus proveedores habituales no iniciaron acciones judiciales, Barraco acordó con sus acreedores y poco más de una década después era uno de los rematadores más activos de la ciudad. 2da. Circunscripción. Expediente 2563, Año 1890, Pedido de Moratoria por crisis de 1890 en Rosario - Domingo Barraco.

Archivo del Museo Histórico Provincial "Dr. Julio Marc", Juzgado Civil y Comercial 2da. Circunscripción. Expediente 2563, Año 1890, Pedido de Moratoria por crisis de 1890 en Rosario - Domingo Barraco. 
Cuadro 1. Situacion patrimonial de domingo barraco al 20/05/1890 (en \$ mn)

BIENES PERSONALES

\begin{tabular}{|c|c|c|}
\hline \multicolumn{3}{|l|}{ ACTIVO } \\
\hline Bienes raíces (incluye depreciación) & 224.147 & \\
\hline propiedad inmueble hipotecada & 64.800 & \\
\hline Acciones en bancos y Sociedades Anónimas & 20.750 & \\
\hline Deudas por cobrar & 29.000 & 338.697 \\
\hline \multicolumn{3}{|l|}{ PASIVO } \\
\hline $\begin{array}{l}\text { Argentine Land an Investment Company } \\
\text { (hipoteca) }\end{array}$ & 28.800 & \\
\hline $\begin{array}{l}\text { The River Plate Trust Loan and Agency } \\
\text { Company (hipoteca) }\end{array}$ & 14.400 & \\
\hline Luis Lagomarcino (hipoteca) & 5.000 & \\
\hline Acreedores varios (pagares) & 58.306 & 106.506 \\
\hline PATRIMONIO NETO & & 232.191 \\
\hline \multicolumn{3}{|l|}{ BIENES COMERCIALES } \\
\hline \multicolumn{3}{|l|}{ ACTIVO } \\
\hline Caja & 910 & \\
\hline Mercaderías & 71.988 & \\
\hline Muebles & 2.023 & \\
\hline Deudores varios & 274.870 & 349.791 \\
\hline \multicolumn{3}{|l|}{ PASIVO } \\
\hline Proveedores & 315.335 & 315.335 \\
\hline
\end{tabular}

Fuente: Archivo del Museo Histórico Provincial "Dr. Julio Marc", Juzgado Civil y Comercial 2da. Circunscripción. Expediente 2563, Año 1890, Pedido de Moratoria por crisis de 1890 en Rosario - Domingo Barraco.

El caso ilumina algunos aspectos relativos al comportamiento de los actores frente a la crisis. En primer lugar, el hecho de que lajusticiacomercial fundamentara su decisión en la valuación de los bienes comerciales de Barraco y no de los bienes inmobiliarios (aunque éstos integraran la porción mayoritaria de su patrimonio), no sólo refiere la brusca caída de los precios inmobiliarios en el año 1890 sino también la incertidumbre respecto al valor futuro de estos bienes, que desestimaba su calificación como garantía de solvencia. Al menos desde 1889, la sobrevaluación de los precios de las tierras asociada a la especulación inmobiliaria se denunciaba como factor desestabilizador de la economía argentina. Junto con la suba del oro y la emisión monetaria, constituye- 
ron las primeras señales críticas de la economía en la visión de sus contemporáneos ${ }^{38}$.

En segundo lugar, la rápida reacción de Barraco frente a la demanda judicial se reveló acertada, considerando que aún circulaba entre la dirigencia local una visión de la crisis como situación pasajera que se sintetizaba en la expresión "crisis del progreso". Como ya se ha señalado, esta expresión no sólo era una figura de la retórica gubernamental sobre la crisis. Su receptividad en la elite económica y en la prensa no oficialista convalidaba las expectativas de una rápida recuperación en función del carácter estrictamente financiero de las perturbaciones ${ }^{39}$.

La desigual percepción de los acreedores respecto a la gravedad de la situación y las condiciones para salir de ella dieron lugar a diferentes actitudes hacia Barraco; las que además implicaban la puesta en práctica de reglas y convenciones estructuradas antes de la crisis. En este marco, pueden interpretarse las acciones emprendidas por las empresas británicas en el caso Barraco. La única entidad que reclamó judicialmente el cobro fue el Banco de Londres, aún cuando este no era el acreedor más importante de Barraco, quien debía sumas mayores a las firmas Rouillón, Marini y Cía y Pinasco \& Castagnino (\$mn 26.850 y $\$ m n$ 25.350, respectivamente).

En general, los bancos británicos mantuvieron durante los años 80 las restricciones al crédito fijadas por los directivos de las casas centrales, quienes explícitamente recomendaban excluir del crédito a clientes riesgosos como los funcionarios de gobierno, especuladores, hombres de negocios y rentistas cuya única garantía fueran las propiedades inmobiliarias. Según el criterio de las entidades financieras británicas, el procedimiento a seguir en función del análisis de la situación en Londres y la experiencia adquirida en la crisis de 1873, era la inmediata demandaju-

38

"No, no queremos oro para los negocios ficticios sobre terrenos valorizados, sin cultivarlos, con perjuicio del que realmente debe poseerlos, el agricultor. No, no queremos préstamos, porque lo que necesitamos es gobierno y hommes de affaire confianza, crédito, seguridad y libertad y no coches con libreas compradas con el sudor del pueblo [...]. Hierro se precisa y no oro.", "El estado económico del país", $E l$ Municipio, año III, n. 801, Rosario, 6 de febrero de 1890.

Juárez Celman sostuvo este argumento hasta sus últimos días de gobierno, tal como puede verse en el mensaje presidencial en ocasión de la apertura de sesiones del congreso, de mayo de $\mathbf{1 8 9 0}$. Los argumentos de la dirigencia política fueron ironizados por The Standard, que bajo el titulo de Crisis Proverbial, comentaba que The average Argentine politician, after a strong dose of proverbial philosophy, tell us that 'no hay mal que por bien no venga'". The Standard, Año XXXI, n, 8289, marzo, 23. 
dicial con el objeto de asegurarse el cobro. Del mismo modo, aunque un poco más tarde, actuó The River Plate Trust, Loan \& Agency, que en 1892 presentó su demanda por cobro de pesos contra Barraco .

Distinto comportamiento asumieron los acreedores locales de Barraco. Podría pensarse que la firma Pinasco \& Castagnino no inició acciones legales por la relación de larga data que existía entre los padres de sus titulares con el padre y el abuelo de Barraco. Pero en realidad, el reclamo judicial no parece haber sido una práctica habitual entre los comerciantes locales, que en esta coyuntura, prefirieron negociar en forma personal con sus deudores. Así procedieron los restantes acreedores, la mayoría de los cuales no tenía relación personal con Barraco. Dada la escasez de circulante y la inexistencia de una perspectiva de reactivación del mercado de tierras en el corto plazo, al acreedor local no le convenía proceder a la ejecución del bien hipotecado en una coyuntura de precios deprimidos y con tendencia a la baja, sino cobrar la deuda en un plazo mayor al estipulado.

En este caso, el crédito habilitado por las casas importadoras más importantes de la ciudad operó a favor de la solicitud de Barraco, puesto que la prosecución de la demanda iniciada por el Banco de Londres podía perjudicar el cumplimiento de sus obligaciones con aquellas. En definitiva, Barraco pudo continuar operando, aunque años más tarde ya no tenía su almacén sino que se dedicaba al remate y venta de fincas y terrenos urbanos.

La institucionalización de esta práctica convalidó la opción de convenir acuerdos que contribuyeran a normalizar las situaciones individuales en lugar de ejecutar a los deudores, de modo que la actividad económica pudiera reiniciarse sin destruir el capital con beneficio para ambas partes. Esta fue el razonamiento de José Terry ${ }^{41}$, en su defensa de una política flexible del Banco Nacional hacia los deudores durante la crisis:

Entre arruinar al deudor ejecutando sus bienes ó darle esperas de años con garantías reales, preferimos lo segundo, por que es temperamento que beneficia, al mismo tiempo á deudor y á acreedor, por que á los efectos de la liquidación general el deudor ha liquidado con

Sobre la demanda de Trust Company, ver Indice de expedientes civiles y comerciales, Archivo de Tribunales Provinciales de Rosario, Año 1892.

41 José A. Terry era profesor de la cátedra de Finanzas Públicas en la Facultad de Derecho de la Universidad de Buenos Aires y fue Ministro de Hacienda en 1893-1895, y en 1904-1906. 
el arreglo y con haber normalizado su situación, y por que no se destruye ó malbarata su capital, ni se ciega una de las tantas fuentes de la riqueza pública. Si de la teoría pasamos á los hechos concretos, ahí tenemos el ejemplo del Banco Nacional que, dando esperas de seis años a sus deudores, se ha colocado en condiciones de salvar sus propios intereses salvando á la vez los de aquellos. - Si el Banco desde el primer día hubiera ejecutado sin compasión a los firmantes de sus letras, no servidas, hoy, el Banco no tendría más dineros en sus cajas, y sus deudores estarían irremisiblemente arruinados (Terry, 1893, p. 19).

\subsection{Juan Canals}

En contraposición con los comerciantes que reinvirtieron sus beneficios en actividades diversificadas manteniendo cierto equilibrio entre activos de distinta liquidez, los empresarios cuyo capital se dirigió casi exclusivamente a la adquisición de tierras, no subsistieron a la crisis. El caso paradigmático fue el de Juan Canals, cuyo fluido contacto con funcionarios gubernamentales, le brindó claras ventajas a la hora de definir la contratación de obras públicas. Canals estaba a cargo de la construcción de las obras del puerto de Rosario, cuya concesión obtuvo del gobierno nacional en 1888. También era contratista de las obras del adoquinado de la ciudad, según convenio firmado con la intendencia de Pedro de Larrechea (1887-1889) y mantenía una estrecha relación con el directorio del Banco de la provincia de Santa Fe.

Este empresario catalán había adquirido numerosos solares urbanos y amplias extensiones de tierras suburbanas, especialmente entre 1888 y 1890, mediante créditos hipotecarios de distintas fuentes. Canals era constructor de obras, propietario de un inquilinato, accionista mayoritario de una Fábrica de Yerba y de la empresa Tranways del Oeste; no obstante, la mayor porción de las utilidades obtenidas en la construcción y el comercio fue invertida en la compra de más tierras. La operatoria corriente de Canals puede ilustrarse en una de sus operaciones. En 1889, cuando los precios de las tierras habían alcanzado su máximo y otros agentes habían dejado de comprar, Canals compró unos terrenos en Bv. Argentino entre Independencia y Orden por valor de $\$ \mathrm{~m} / \mathrm{n} 350.000$, pagando $\$ \mathrm{~m} / \mathrm{n} 100.000$ al contado, y tomando Cédulas hipotecarias Serie C por los $\$ \mathrm{~m} / \mathrm{n} 250.000$ restantes.

El predominio de la inversión en tierras en la estrategia de Canals se evidenciaba en la evolución de las sociedades de las que fue titular y accionista. Entre ellas, Canals, Dam y Cía., creada en 1887 con el objeto 
de distribuir y comercializar productos de almacén al por mayor. El capital inicial de la firma era de \$mn 150.000, de los cuales Canals aportó $\$ \mathrm{mn} 100.000$ (provenientes de la diferencia entre el activo y pasivo de Escayola, Canals y Cía., su anterior empresa), mientras que Jóse Dam y José Preto aportaron $\$ m n 25.000$ en efectivo respectivamente ${ }^{42}$. En setiembre de 1890 , la sociedad se disolvió. Entonces, su activo se integraba por \$mn 80.730,81 en acciones de la Fábrica de yerba La industrial Paraguaya y \$mn 642.212,5 en la cuenta del socio Juan Canals. El pasivo de la empresa ascendía a $\$ \mathrm{mn} 352.943,31$ en deudas a terceros ${ }^{43}$.

En los años 80, Canals era considerado uno de los hombres de negocios más destacados de la ciudad, emulado por sus pares y presentado como el arquetipo del empresario exitoso. Su acceso privilegiado a la esfera gubernamental se complementaba con la disponibilidad del crédito de los bancos ingleses que financiaron sus operaciones inmobiliarias. Los cuantiosos préstamos hipotecarios que el Banco Inglés del Río de la Plata otorgó a Juan Canals entre 1888 y 1890, revelan que la política restrictiva de los bancos comerciales británicos en Argentina no siempre fue aplicada por los gerentes de las sucursales locales, especialmente durante los años ochenta, cuando la valorización de los terrenos parece haber constituido un atractivo suficiente para quienes aprobaron estos prestamos ${ }^{44}$.

Sus relaciones atrajeron a varios operadores locales ávidos de hacer negocios con él, que no dudaron en acompañar riesgosas operaciones que al cabo de poco tiempo, los llevaron a formar parte del nutrido conjunto de acreedores de Canals. Vale referir aquí el infausto caso del Banco Sindical En octubre de 1888, Emilio, Carlos y Juan Ortiz, Federico Lozano, Nicasio Vila, Gregorio Machain, Carlos W. Blyth, Fermín Beretervide y Lástenes Colombres, compraron un terreno de cerca de 2 millones de varas por $\$ m n 200.000$, que fue fraccionado y vendido en $\$ m n$ 1.155.000 pesos. Con el capital obtenido en éste y otros negocios similares, los citados formaron el Banco Sindical, al cual ingresó Canals, por intermedio de Emilio Ortiz y de Federico Lozano que

A.T., Caja 26, legajo 866, Contrato de la sociedad "Canals, Dam y Cía", 3 de enero de 1887.

43 A.P.N.S.F., Protocolo Luis Suárez, año 1890, Escritura de la Disolución de la sociedad Canals, Dam y Cia.

44 Ver Archivo Torriglia, Caja 29, legajo 928, "Informe de los terrenos del Banco de Londres y Rio de la Plata entregados por Juan Canals", 6 de octubre de 1891. Sobre la política de los bancos ingleses, Jones, 1977, p. 36. 
"acababan de hacer un buen negocio con él". Se acordó la emisión de 60.000 acciones de cien pesos cada una, representando un capital de 6 millones de pesos. Canals tasó sus propiedades al elevado precio de 6 millones de pesos moneda nacional, recibiendo 2 millones en acciones y 2 millones en efectivo. Los 2 millones restantes se registraron como deuda a su favor, contra la garantía particular de los miembros del directorio "ocasionando lo último una desavenencia que casi dio por tierra con la asociación, pues se retiraron dos de los tres socios principales" ${ }^{45}$.

Habida cuenta del acuerdo mediante el cual los socios garantizaron los negocios de Canals con sus bienes personales, la caída de los precios de la tierra y las demandas contra el Banco Sindical, comprometieron críticamente los patrimonios de los socios y accionistas del banco; de modo que éstos acordaron formar una comisión liquidadora y transferir definitivamente el capital del Banco a Canals. Así, en octubre de 1891, la comisión compuesta por Emilio Ortiz, Federico Lozano, Lástenes Colombres, Juan Crespo, José Dam, Manuel Beretervide, José Monterola, Nicasio Vila y Carlos Blyth enajenó a favor de Canals el activo y pasivo del Banco quedando obligado Canals a abonar a los accionistas en pago de sus acciones un $40 \%$ del valor total de las mismas en tierras de las adquiridas por el referido contrato tomando como base para la operación el costo de las expresadas tierras ${ }^{46}$.

Unos días antes, Canals había traspasado al BIRP numerosas propiedades urbanas en pago de deudas contraídas entre 1889 y 1890 (cuando la inflación de los precios ya evidenciaba el alto riesgo de las inversiones en tierras). La transferencia de las propiedades de Canals a favor de otras entidades, además del BIRP, $i$. e., Banco de Londres y Río de la Plata, Banco Provincial de Santa Fe, Banco Nacional y el Banco Sindical, se sucedió durante los años 90. Si bien en 1899, se hizo público un arreglo entre Canals y el gobierno provincial para blanquear sus deudas a fin de que volviera a ejercer el comercio, Canals nunca logró recuperarse de la quiebra ${ }^{47}$. vincia de Santa Fe, Protocolo del Escribano Jacinto Correa, año 1891, Escritura del 13 de octubre de 1891. En el mismo acto, Federico Lozano que poseía acciones por valor nominal de \$mn 398.000 entregó en propiedad y dominio, siete inmuebles ubicados en el centro sur y centro oeste de la ciudad como pago del $40 \%$ del valor nominal de tales acciones.

47

Cfr. "La historia de un banco.", El Municipio, Año IV, n. 891, 29 de mayo de 1890.

Cfr. El Municipio, diciembre de 1899. 
Ninguna de las obras públicas contratadas con Canals se concretó. Las obras del puerto se suspendieron en marzo de 1890, rescindiéndose el contrato en 1892, luego de la quiebra del empresario ${ }^{48}$. Las obras del adoquinado también se suspendieron cuando la Municipalidad no pudo disponer de los fondos del empréstito destinado a su realización depositados en el Banco Provincial ${ }^{49}$. Pero además, las irregularidades en la contratación del adoquinado fueron tema de controversia durante toda la década. Para su realización, la Municipalidad había contratado en 1887 un empréstito de $\$ 5.000 .000$ oro, que fue depositado en el Banco Provincial de Santa Fe en una cuenta a nombre de Canals. Hasta setiembre de 1890, Canals extrajo dinero de la cuenta mediante la presentación de certificaciones parciales donde la municipalidad aprobaba las cuadras adoquinadas. En octubre de 1890, un mes antes de la caída de la casa Baring, se cambió el sistema. Canals y el director del Banco Provincial, acordaron transferir el saldo de la cuenta de Canals $(\$ 4.200 .000 \mathrm{mn})$ a una cuenta de la Municipalidad de Rosario, estatizando la deuda de Canals con el municipio ${ }^{30}$.

Las denuncias contra el "empresario tiburónico" como lo denominaba el diario El Municipio, convergieron en un discurso opositor al oficialismo que hacia mediados del año noventa articuló la reacción de la elite local contra la administración de Larrechea, las criticas a la política clientelar y emisionista del Banco de la Provincia y la corrupción del gobierno nacional, acreditando una explicación de la crisis asociada a la

${ }^{48}$ Junto con las demás obras que el célebre empresario tiburónico había ideado para transformar el Rosario en una ciudadfabulosa, han sido suspendidos los trabajos que se hacian en el puerto [...]. A ese resultado llegó el empresario tiburónico, después de retratarse con un ministro y un futuro, muy futuro sucesor en el trono del gran mercader", "Las obras del puesto paralizadas", El Municipio, año III, n. 829, Rosario, 13 de marzo de 1890.

Las tres cuartas partes del monto total del empréstito quedaron inmovilizadas en la cuenta de la Municipalidad en el Banco Provincial. Su devolución al Municipio por parte del gobierno provincial se efectivizó diecisiete años más tarde. Las obras del adoquinado se reiniciaron en 1893. Cfr. MUNICIPALIDAD DE ROSARIO, $\mathrm{Me}$ moria presentada al HCM por el Intendente Gabriel Carrasco, año 1890, Rosario, 1891, p.5-11; MUNICIPALIDAD DE ROSARIO, Memoria presentada al H.C.M. por el Intendente Nicasio Vila, años 1906-1908, Rosario, 1909, pp. XX-XXIII.

Las irregularidades en la contratación del adoquinado con Canals fueron denunciadas por El Municipio durante el año noventa, pero la irregular intervención del Banco Provincial en el asunto salió a la luz años después en varios artículos publicados en noviembre y diciembre de 1899 . 
inmoralidad política y económica, cuya trascendencia se amplificaría con la revolución del parque liderada por Leandro Alem y la renuncia del presidente Juárez Celman.

Canals ya representaba entonces al empresario inescrupuloso y especulador, uno de los tantos "particulares interesados en lucrar inconsideradamente á espensas del vecindario" que, mediante la repartición de utilidades con funcionarios municipales y provinciales, obtenía sin ningún mérito comprobable las más fabulosas concesiones y el crédito necesario negado por el Banco Provincial a la producción y al comercio ${ }^{51}$.

Al Ministro del Interior Teniente General Julio a. Roca.

El gobierno de Juárez, huyendo de la honradez de las licitaciones, concedió al empresario señor Canals el privilegio exclusivo para la construcción y explotación de los muelles y malecones del Rosario por un plazo de 20 y 40 años, proporcionándole máquinas, útiles y medios, para fijar las tarifas y cobrar los derechos; para engullirse sin control ni responsabilidad, una buena parte de las rentas de la nación y de la provincia ${ }^{52}$.

A mediados del año 90, el papel de los grupos de inversión británicos en la crisis era mencionado sólo ocasionalmente por la prensa local. La relación entre la crisis argentina y las operaciones de la Casa Baring no había adquirido entonces un lugar central en la interpretación de la crisis, aún luego de conocerse la liquidación de la firma en noviembre de 1890. Este suceso calificado de "inesperado" fue percibido como un elemento agravante de la situación del país en tanto el simple hecho de haber suspendido sus transacciones - ya que no los pagos - nos daña considerablemente, ya sea por lo que se refiere a la conversión de las cédulas hipotecarias, ya bien por las tentativas de rescisión del contrato de las obras sanitarias de Buenos Aires ${ }^{53}$.

Cfr. "¿Quiénes son los socios de Canals? ¿Cuáles sus atractivos?", El Municipio, año III n. 809, Rosario, 15 de febrero de 1890; "Inspección del banco provincial de Santa Fe", El Municipio, año III, n. 829, Rosario, 13 de marzo de 1890; "El Banco Provincial. Su influencia en la crisis. La defensa del comercio", El Municipio, Año III, n. 830, Rosario, 14 de marzo de 1890.

52 Publicado en la sección de Noticias Permanentes de El Municipio, desde el 6 setiembre hasta finales del año $\mathbf{1 8 9 0}$. 
La liquidación de la firma hizo evidente la generalización de la crisis, cuya profundidad había sido desestimada por aquellas expectativas enraizadas en el progreso agrícola de la región, dando lugar finalmente a una visión inequívocamente sombría sobre la situación económica del. país. El oro a 317 es el caos. No hay comercio posible ni vida miserable ni tráfico ni operación ni existencia. Ruina, nada mas que ruina. Sin plata, sin gobierno, sin libertad, sin esperanza, sin porvenir y sin un mendrugo de pan que llevara la boca, la desesperación del obrero alcanza su límite ${ }^{54}$.

\subsection{José Arijón ${ }^{55}$}

La trayectoria del español José Arijón comparte con los casos descriptos, la activa intervención en la compraventa de tierras urbanas durante los años 80. Arijón se dedicaba a la exportación de alfalfa, cueros y lanas. En 1882 adquirió una extensa lonja de terreno con salida al río Paraná en el área norte de la ciudad. Cuatro años más tarde, el Ferrocarril Buenos Aires y Rosario levantó sus depósitos y terminales pocas cuadras al sur de esas tierras, a lo que siguió el establecimiento de los depósitos de las empresas exportadoras, importadoras e industriales más grandes de la ciudad. La demanda comercial e industrial de los terrenos ubicados entre las instalaciones ferroviarias y la ribera, produjo la acelerada valorización de la propiedad de Arijón, a quien la venta de solares le proporcionó entonces las ganancias más altas del sector.

En principio, la crisis del noventa no afectó seriamente los negocios inmobiliarios de Arijón, quien compró entonces tierras a precios deprimidos, y ofició de prestamista cobrando altos intereses. No obstante, en 1898 salieron a la luz las dificultades financieras del Banco de España y del Rosario, cuyo directorio integraba. Las irregularidades en el manejo de la cuenta especial a nombre de Arijón, motivaron la convocatoria a una asamblea de accionistas en agosto de 1899. En ella, Arijón explicó que para arreglar las cuentas pendientes de su ex gerente Alejandro Zuker con el Banco, entre abril y mayo de 1890 había recibido de éste un conjunto de valores muebles e inmuebles que fueron registrados en una cuenta abierta en los libros de la institución bajo el nombre deJosé Arijón Cuenta especial por encargo del Directorio del Banco, a la sazón integrado por Arijón, Díaz y Loizaga.

En el mismo acto, los bienes de la cuenta especial de Arijón (integrados por acciones de distintas empresas - algunas de ellas en liquidación

54 "A 317", El Municipio, año IV, n. 1032, 23 de noviembre de 1890.

55 La trayectoria de José Arijón ha sido analizada en detalle en Lanciotti. 2005a. 
- y varios terrenos urbanos muy devaluados) se transfirieron al banco, y la asamblea declaró a Arijón exento de responsabilidad en el asunto. Sin embargo, la renuncia del entonces Director titular de la entidad, José Castagnino, y la estrecha relación de negocios que mantenían Joaquín Díaz, Alejandro Zuker y José Arijón ameritan desconfiar de la participación involuntaria de Arijón en este asunto, sobre todo al observar que el mismo terminó en la transferencia al banco, de activos de difícil realización cuya adquisición era parte de los negocios particulares de Zúker y Arijón ${ }^{56}$.

A finales de la década, Arijón se había retirado prácticamente del comercio de exportación. Con la reactivación del mercado inmobiliario, Arijón reanudó las ventas de terrenos de grandes dimensiones a empresas urbanizadoras y operadores inmobiliarios, obteniendo nuevamente una rentabilidad promedio muy elevada. Intervino además en forma creciente en el mercado de crédito informal, prestando dinero con garantía hipotecaria a comerciantes e industriales.

La consolidación de su patrimonio y su posición en el sector inmobiliario hacia finales de la primer década del novecientos perfilaron la óptima situación de Arijón en la crisis de 1913-1914. A diferencia de lo actuado en los años 80, durante la expansión del novecientos, Arijón concentró sus inversiones inmobiliarias en la populosa quinta sección, operó exclusivamente con el segmento de la demanda intermedia y sólo prestó dinero con garantía hipotecaria a poderosos comerciantes, industriales o rentistas cuyas propiedades bien localizadas y fácilmente realizables, no presentaran riesgo en caso de ejecución. La estructuración de la actividad inmobiliaria bajo un criterio claramente conservador favoreció el usufructo de las oportunidades que la crisis de 1913 le brindó para ampliar su patrimonio, y consolidar su posición en desmedro de sus deudores. Ante los incumplimientos de pago que comenzaron a sucederse desde el año 1913, Arijón rápidamente acudió a la vía legal para ejecutar las propiedades garantidas, eludiendo todo arreglo con los deudores. Por la vía de la ejecución hipotecaria, incorporó a su patrimonio importantes propiedades urbanas localizadas en el centro de la ciudad, así como propiedades rurales en las provincias de Santa Fe y Córdoba, y volvieron a sus manos algunos de los terrenos vendidos en el área fabril norte. 


\section{Las relaciones comerciales y la organización de las empresas en función de la experiencia de la crisis}

En el siglo diecinueve, las empresas inmobiliarias eran usualmente empresas familiares que operaban como sociedades de hecho y sociedades comanditarias, en las que sus propietarios mantenían vínculos parentales o amicales. Particularmente, durante los años 80 se crearon numerosas sociedades de hecho que reunían los capitales de varios agentes con el fin de emprender ocasionales operaciones inmobiliarias de magnitud. Algunas de estas sociedades constituidas para concretar negocios ocasionales se formalizaron luego en sociedades comerciales y en sociedades anónimas.

En las empresas familiares o amicales, la confianza era el resultado del contacto interpersonal originado en los vínculos familiares o profesionales y de la reputación de los agentes cuyo rango dependía de su posición en las redes sociales de pertenencia ${ }^{57}$. En los casos en que los vínculos societales resultaron de la realización de operaciones en común, la confianza se construyó en torno a la reputación adquirida por los agentes en función de las oportunidades de negocios provenientes de sus relaciones con el gobierno y los bancos, tal como se observa en la experiencia del Banco Sindical. En ambos tipos de sociedades, primaban relaciones de confianza personal, cuya fuente era el parentesco, la familiaridad o el interés por asociarse con quienes proveían oportunidades de negocios según el caso.

A finales de los años ochenta, la extensión de los negocios efectuados sobre la base de la confianza fundada en el interés había contribuido a elevar el riesgo económico de las inversiones inmobiliarias que resultaron de disposiciones orientadas exclusivamente por las expectativas de beneficios asociados con el acceso a los espacios de decisión política y al crédito inmobiliario, tal como se representa en la trayectoria de Juan Canals. La experiencia de la crisis puso en evidencia que la confianza basada en este tipo de contacto interpersonal podía distorsionar las perspectivas que convalidaban las decisiones de inversión, comprometer el patrimonio de las empresas, elevar los costos de transacción y en definitiva, debilitar la capacidad de gestión y la pervivencia de las empresas,

La teoría económica define como confianza a la probabilidad subjetiva con la que un actor o un grupo de actores ejecuta determinada acción, independientemente de que pueda controlarla en contexto con aquello que incida en su acción o en los resultados de la misma. 
en la medida en que se subsumieran los objetivos de las organizaciones a los intereses particulares de los socios, como parecen mostrar los casos del Banco Sindical y del Banco de España y del Rosario ${ }^{58}$.

La posición de liderazgo alcanzada por empresarios como Canals y por empresas de similar trayectoria y estrategias como Alvarado \& Puedo o Emilio Ortiz \& Cía en los años 80, expone el predominio de aquellas relaciones comerciales constituidas sobre la base de la confianza fundada en el interés particular de los actores en un entorno de ideas adscriptas al progreso como resultado de la libre acción de los agentes en el mercado. La emergencia de la crisis y las representaciones constituidas en el transcurso de su experiencia invirtieron la imagen positiva del empresario astuto y bien relacionado que predominó en la década del progreso. El antes emulado "hombre de fortuna", devino en el empresario inescrupuloso, especulador inmoral cuya riqueza provenía del afán de lucro desmedido y de oscuros negocios particulares que peijudicaban a los sectores productivos, conduciendo al país a la ruina económica. La contraposición entre especuladores y productores publicitada en los primeros 90 , fue continuada por una resignificación de la figura del empresario que tendió entonces a considerar otros valores, como ser la continuidad de sus negocios, la solvencia de las empresas y la elusión del riesgo.

Paralelamente, la crisis produjo una revisión de los criterios de confiabilidad basados en las lealtades personales, que fueron abriendo paso a mecanismos más impersonales donde la confianza era el resultado de una evaluación de las condiciones y evolución de las variables económicas e institucionales que influían en el sector inmobiliario, así como de la reputación adquirida por los empresarios en la dirección de sus negocios, sobre la base de la continuidad y trayectoria de sus empresas. Así, la habilidad, la competitividad y la capacidad de respuesta frente al factor de incertidumbre, particularmente relevante durante la crisis, fueron desplazando a la lealtad tradicional como único soporte de la confianza, dando origen a una confianza más reflexiva ${ }^{59}$.

El desplazamiento en los mecanismos y en las fuentes de la confianza que estructuraban las relaciones comerciales promovió la formación de empresas más estables en el nuevo siglo, entre ellas las sociedades anónimas urbanizadoras, donde las decisiones estuvieron en manos de un conjunto de directivos en vías de profesionalización que desarrollaron

Sobre Alvarado \& Puccio y Emilio Ortiz \& Cía, Lanciotti, 2003.

Sobre la confianza como mecanismo coordinador del mercado, y el surgimiento de la confianza reflexiva: Adler, 1999. 
pautas de inversión basadas en una evaluación de las tendencias del mercado en función de las direcciones de expansión territorial y la cobertura de servicios urbanos de infraestructura.

Por cierto, esta dirigencia mantuvo un acceso privilegiado a las instancias de poder local y regional, pero la crisis había revelado que dicha condición no era suficiente para garantizar la prosperidad económica al menos desde una perspectiva diferente de los negocios en la que los criterios que definían el éxito o el fracaso de una empresa habían integrado a la prosecución de la rentabilidad elevada, la continuidad y solvencia de las organizaciones, a través de la consolidación de determinados segmentos del mercado y la disminución del riesgo económico ${ }^{60}$.

\section{Algunas conclusiones}

En el proceso de configuración de la sociedad urbana de entresiglos, la crisis del 90 constituyó un acontecimiento clave. La crisis impulsó el desplazamiento de prácticas institucionalizadas que habiendo sido funcionales para los sectores dirigentes en la década del progreso, se volvieron impracticables, inconvenientes o disfuncionales luego de la crisis. Las trayectorias frustradas, las dificultades financieras y la quiebra de quienes hasta entonces habían sido considerados exitosos hombres de negocios y admirados emprendedores, advirtieron a los empresarios que los mecanismos y estrategias que habían posibilitado su inserción en aquella elite de heterogéneo origen y composición social que se veía a sí misma como artífice del progreso económico y social de la ciudad moderna y liberal, no garantizaban su permanencia.

En función de la continuidad de los negocios de los empresarios e inversores que participaron en el negocio inmobiliario durante la expansión urbana de los años 80 , se establece que en un primer momento, las estrategias exitosas fueron aquellas que lograron establecer cierto equilibrio entre las inversiones especulativas de corto plazo y las inversiones de capital fijo a largo plazo en activos de distinta liquidez. La inversión de los beneficios del comercio en la compraventa de terrenos urbanos generó beneficios significativos en el corto plazo, pero también originó un sobreendeudamiento que dio lugar a la multiplicación de empresas insolventes, y a la devaluación de los activos de empresas y particulares, muchos de los cuales terminaron en la quiebra y liquidación. 
Además de la proporción de capital destinada a la inversión inmobiliaria y de la moneda en la que se negociaron los préstamos, la evolución de los negocios dependió de la percepción crítica respecto a los cambios en el mercado elaborada por los agentes. Quienes tomaron en cuenta el valor estimado del terreno de acuerdo a su localización, su uso potencial, las tendencias del mercado y las garantías del comprador en el caso de que la venta fuera financiada, evaluando en definitiva los riesgos de cada operación, obtuvieron mejores resultados a largo plazo, y llegaron a liderar el sector inmobiliario a partir del novecientos.

Por el contrario, los agentes que no registraron la tendencia alcista de las tierras y adquirieron tierras a precios elevados entre 1889 y principios de 1890, en áreas excluidas de las direcciones de expansión territorial estructuradas por la localización de las actividades económicas urbanas, basándose en una percepción optimista del juego de las fuerzas económicas en el mercado que se resistía a considerar los indicios de un desequilibrio ya presentes en 1889 , acusaron fuertemente el impacto de la crisis, llegando incluso a la ruina.

La experiencia de la crisis afectó visiblemente las decisiones de inversión. La disminución de la rentabilidad en los años noventa desalentó la inversión inmobiliaria en tierras entre los operadores ocasionales muy diversificados. Luego de trasponer la crisis, comerciantes y empresarios encontraron destinos más rentables y mejores oportunidades de inversión en el arrendamiento de parcelas rurales, la producción agrícola, la ganadería - que comenzó a recuperarse desde mediados de la década del noventa - y también en la industria ${ }^{61}$.

La caída de los precios de la tierra operó en sentido contrario para aquellos que mantuvieron una inserción significativa en el sector, quienes oportunamente adquirieron propiedades subvaluadas a la espera del alza de precios futura. Ambas alternativas estructuraron divergentes tra-

\footnotetext{
Schlieper. En 1890, Hermann Schlieper se instaló en Buenos Aires para trabajar en E. Tomquist \& Cía, dejando la casa importadora en Rosario a cargo de Ricardo Schlieper. En 1900, la firma Schlieper y Compañía dejó de comerciar bienes importados para dedicarse a la distribución del azúcar producido por Refinería Argentina en el interior del país y al año siguiente, abrió una destilería (Lloyd, 1911, p. 671). Otro ejemplo lo constituye el caso de Juan B. Quintana, que integró a su actividad de barraquero, la producción de arneses y suelas para el calzado. Un proceso de eslabonamiento hacia atrás inició la firma Claus Hermanos, exportadores de cueros y pieles que instalaron una fábrica de cola y una fabrica de aceite, insumos necesarios para su actividad, que terminaron comercializando en el mercado local, Lloyd, 1911, p. 674.
}

${ }^{61}$ Un ejemplo de la diversificació 
yectorias. Mientras algunos operadores disminuyeron su participación en el sector inmobiliario o incluso se retiraron, otros consolidaron su inserción en él. En cada caso, las decisiones de los agentes dependieron del ámbito de sociabilidad en el que se formaron, de la composición y magnitud del capital económico y de los recursos sociales disponibles, pero también de la elaboración de una percepción crítica sobre los destinos de inversión en relación con la disfunción del mercado de tierras en la etapa anterior y de las condiciones de riesgo e incertidumbre evidenciadas por la crisis ${ }^{13}$.

La comparación de las trayectorias empresariales permite observar el desplazamiento de prácticas orientadas por una lógica máximizadora de las ganancias ajustada a la visión optimista sobre el vertiginoso progreso económico en los expansivos años 80, hacia la adopción de criterios más conservadores en las decisiones de inversión y la configuración de relaciones comerciales adecuadas a una disposición favorable a la cooperación sobre la base de una confianza reflexiva orientada a disminuir el riesgo económico. Este desplazamiento se articuló con la adhesión a un discurso público centrado en los principios de austeridad, credibilidad y defensa de la producción en la década del 90, cuyos elementos se mantendrían vigentes en las representaciones de lo económico en el nuevo siglo.

En los años 80, los empresarios líderes del sector inmobiliario habían intervenido activamente en la compra de tierras en áreas no urbanizadas a precios sobrevaluados siguiendo un patrón territorial disperso y disociado de las pautas de inversión en obras y servicios de infraestructura urbana, y financiando sus inversiones mediante el crédito hipotecario. Estas prácticas definieron un comportamiento que convalidaba la operatoria de empresas poco solventes, cuyos patrimonios combinaban un importante pasivo con activos de escasa liquidez. ,

Como resultado de la evaluación crítica sobre la profunda recesión del mercado inmobiliario durante los años 90 , los empresarios que continuaron operando en el sector modificaron este comportamiento. En la nueva fase de expansión urbana iniciada en el novecientos, los empresarios implementaron distintas estrategias en función de asegurar sus inversiones, consolidar segmentos del mercado, compartir riesgos y eliminar a los competidores. La especialización en nichos de mercado, la

62 La estrategia de diversificación seguida por la empresa inmobiliaria Echesortu \& $\mathrm{Ca}$ sas, por ejemplo, se reveló adecuada en el largo plazo, habida cuenta de su notable expansión (Lanciotti, 2003). 
concentración de inversiones en áreas urbanas específicas cuya urbanización fuera asegurada por la cobertura de servicios urbanos de infraestructura contratados por el municipio, la selección de la clientela sobre la base de su solvencia, y la utilización de la ejecución hipotecaria en lugar de la negociación con los deudores, indican un cambio en la perspectiva del empresariado frente a las condiciones de un mercado inestable cuyas fluctuaciones y desequilibrios habían sido reveladas por la crisis del 90.

Asimismo, la experiencia de la crisis impulsó un cambio en las formas de organización empresarial, dando origen a las sociedades anónimas urbanizadoras. La intervención conjunta en las nuevas urbanizaciones y el desarrollo de inversiones con alto grado de certidumbre a partir de la especialización en la comercialización de tierras suburbanas, la segmentación del mercado y la delegación de funciones directivas en manos de un grupo de empresarios que concentraban recursos informacionales de primer orden, acceso directo al gobierno de la ciudad y capacidades gerenciales adquiridas en el manejo de sus actividades comerciales, marcaron un nuevo rumbo en los negocios inmobiliarios. A partir de entonces, la formación de una oferta oligopólica por sección y la existencia de barreras de entrada en la comercialización de terrenos suburbanos, limitaron las posibilidades de ascenso social que habían alentado la intervención de numerosos operadores durante la fase inicial de expansión del mercado inmobiliario.

El proceso consignado nos permite acotar una vez más los límites de la racionalidad empresarial, por cuanto revela que los agentes económicos evalúan las oportunidades y examinan los riesgos en función de complejos esquemas de percepción, los cuales son reelaborados en el transcurso de la experiencia empresarial frente a coyunturas económicas variables, donde la información circula en forma asimétrica y la experiencia se construye históricamente, lo que implica que la mejor opción posible en determinada situación devenga en la estrategia equivocada en otro contexto.

\section{Referencias bibliográficas}

ADLER, Paul S., Market, Hierarchy, and Trust: The Knowledge Economy and the Future of Capitaiism, [online]. Junio 1999, [citado 30 octubre 2003], pp. 1-55.

Disponible en la World Wide Web <http://ssrn.com/abstract=186930>. ALONSO, Paula, "La Tribuna Nacional, Sud-América y la legitimación del poder (1880-1890)", Entrepasados. Revista de Historia, año XII, n 24/25, 2003, pp. 29-66. 
ALONSO, Paula, "La Tribuna Nacional y Sud-América: tensiones ideológicas en la construcción de la "Argentina moderna" en la década de 1880", Alonso P. (comp.), Construcciones impresas. Panfletos, diarios y revistas en la formación de los Estados nacionales en América Latina, 1820-1920, Buenos Aires: FCE, 2004.

BOTANA, Natalio y GALlo, Ezequiel, De la República posible a la República verdadera (1880-1910), Buenos Aires: Ariel Historia, 1997.

BRAGONI, Beatriz, "Gobierno elector, mercado de influencias y dinámicas políticas provinciales en la crisis política argentina del 90", Entrepasados. Revista de Historia, año XII, n 24/25, 2003, pp. 67-99.

CHI A RA MONTE, José Carlos, Nacionalismo y liberalismo económicos en Argentina, Buenos Aires: Hyspamérica, 1986.

CORTÉS CONDE, Roberto, El Progreso Argentino. 1880-1914, Buenos Aires: Sudamericana, 1979.

, Dinero, deuda y crisis. Evolución fiscal y monetaria en la Argentina 1862-1890, Buenos Aires: Sudamericana, 1989.

, La economía argentina en el largo plazo (siglos XIX y XX), Buenos Aires: Sudamericana, 1997.

DELlA PAOLERA, Gerardo y TAYLOR, Alan, Tensando el ancla. La Caja de Conversión argentina y la búsqueda de la estabilidad macroeconómica, 1880-1935, Buenos Aires: FCE, 2003.

DIAZ, Alejandro Carlos, Ensayos sobre la historia económica argentina, Buenos Aires: Amorrortu, 2002.

FERNANDEZ, Alejandro, Un 'mercado étnico' en el Plata: emigración y exportaciones españolas a la Argentina, 1880-1935, Madrid : Consejo Superior de Investigaciones Científicas, 2004.

FERNANDEZ, López Manuel, Cuestiones económicas argentinas, Bogotá: AZ Editora, 2000.

FORD, Alec, El patrón oro: 1880-1914, Inglaterra y Argentina, Buenos Aires: Editorial del Instituto, 1966.

GAllo, Ezequiel, La Pampa Gringa. La colonización agrícola en Santa Fe (1870-1895), Buenos Aires: Sudamericana, 1984.

GERCHUNOFF, Pablo y LLACH, Lucas, El ciclo de la ilusión y el desencanto. Un siglo de políticas económicas argentinas, Buenos Aires: Ariel, 2003.

INGENIEROS, José y LUGONES, Leopoldo (dirs.), La Montaña. Periódico Socialista Revolucionario-1897-, Buenos Aires: UNQ, 1996.

JONES, Charles, "Commercial Banks and Mortgage Companies", D.C.M Platt, Business Imperialism 1840-1930. An inquiry based on British experience in Latín America, Oxford: Oxford University Press, 1977.

LANCIOTTI, Norma, "Las empresas inmobiliarias en la expansión inicial de las ciudades portuarias argentinas. Organización, prácticas y estrategias", Rosario, 1880-1914, Anuario IEHS, ${ }^{\circ}$ 18, Tandil, 2003: 341-366.

, Mercado inmobiliario en Rosario (1885/1914). Racionalidad empresarial y Configuración del espacio urbano, Tesis de Doctorado, Facultad de Humanidades y Artes - Universidad Nacional de Rosario, 2004 (inédita). 
LANCIOTTI, Norma, "Las estrategias del empresariado inmigrante frente a la expansión del mercado inmobiliario, Rosario, 1870-1914", Estudios Migratorios Latinoamericanos, $\mathbf{n}^{\circ}$ 55, Buenos Aires: Cemla, 2005

, "Las transformaciones de la demanda inmobiliaria urbana y el acceso a la propiedad familiar", Rosario 1885-1914", Revista Ciclos en la historia, la economía y la sociedad, $\mathbf{n}^{\circ}$ 28, Buenos Aires: IIHES-FCE-UBA, 2005.

LLOYD, Reginald, Impresiones de la República Argentina en el Siglo XX. Su historia, gente, comercio, industria y riqueza, Buenos Aires-Londres: Cia Sudamericana de Billetes, 1911.

POLLARD, Sidney, La conquista pacífica. La industrialización de Europa, 1760-1970, Zaragoza: Prensas Universitarias de Zaragoza, 1992.

ROCCHI, Fernando, "La armonía de los opuestos: industria, importaciones y la construcción urbana de Buenos Aires en el período 1880-1920", in Entrepasados. Revista de Historia, año IV, n 7, Buenos Aires, 1994: 43-66.

"En busca del empresario perdido: los industriales argentinos y las tesis de Jorge Federico Sábato", in Entrepasados. Revista de Historia, año V, ${ }^{\circ} \mathbf{1 0}$, Buenos Aires, 1996: 76-82.

, "El imperio del pragmatismo: Intereses, ideas e imágenes en la política industrial del orden conservador", Anuario del IEHS, $\mathbf{n}^{\circ}$ 13, Tandil, 1998: 99-130.

SALVATORE, Ricardo, "The Normalization of Economic Life: Representations of the Economy in Golden Age Buenos Aires, 1890-1913", Hispanic American Historical Review, ${ }^{\circ}$ 81:1: Duke University Press, february 2001: 1-44.

SMITH, Adam. Investigación sobre la naturaleza y causas de la riqueza de las naciones, México: FCE, 1958

TERRY, José Antonio, La crisis 1885-1892. Sistema Bancario, Buenos Aires: Imprenta M. Biedma, 1893.

WILLIAMS, John, Argentine International Trade Under Inconvertible Paper Money, 1880-1890, NY: Greenwood Press, 1969. 